\begin{tabular}{|c|c|c|}
\hline & PORT SAID ENGINEERING RESEARCH JOURNAL \\
\hline
\end{tabular}

\title{
Analysis of Residential Façade Patterns from Acoustic Viewpoint
}

Sara G. Eltarabily ${ }^{l}$, Ashraf Elmokadem ${ }^{2}$, Mostafa R. Ismail ${ }^{3}$

\begin{abstract}
Façade's formation as an integrated system can be used in the acoustic protection process when effect on noise reflections and noise levels in urban streets. In order to know how to use façade morphology as an effective strategy for noise reduction, its elements should be well analyzed; for example: the impact of balcony shape, dimensions, and materials. Egyptian façade's patterns seem to be typically designs and rhythmic formation with their typical floors, balconies, and windows. The Egyptian code for construction determined some geometric parameters that organize the design process. As a result; this paper is considered an approach to determine the main geometric aspect of Egyptian residential façades through analyzing some cases of Egyptian residential projects, in order to be presented in future studies concerning in assessing noise propagation.
\end{abstract}

\section{INTRODUCTION}

\subsection{Effect of façade's shape on noise levels}

Façades as a part of urban areas components; play an important role in noise propagation because of its effect in sound reflections. The buildings façades in the street canyon effect on sound levels, traffic noise from the street can be reflected to the street by balcony fronts and other architectural details, increasing the noise.

Façades can improve sound insulation by using high performance components, but it cannot be sufficient for economic reasons so that the formation by façade shape should be taken into consider. Designing façade morphology like (overhangs, protrusions, recesses, parapet type) as an integrated system is an alternative strategy that differs from using components with high performing systems.

Façade surface shape also can effect on sound reflection process, which based upon the assumption that in most major cities the cases of building façades tend to consist large smooth planes - act like specularly reflecting surface on which can locate diffusers - broken up by protrusions and recesses due to variety of architectural details, where there is a discontinuity regions as shown in Figure 1.

\footnotetext{
${ }^{1}$ Architecture and Urban Planning Department, Faculty of Engineering, Port Said University, Port Said, Egypt, Email: saraeltarabily@gmail.com

2 Architecture and Urban Planning Department, Faculty of Engineering, Port Said University, Port Said, Egypt, Email: elmokadem1@gmail.com

3 Architecture Department, Faculty of Engineering, Ain Shams University, Cairo, Egypt, Email: mostafa_ismail@eng.asu.edu.eg
}

Façade can be modeled in mixed specular and diffuse reflections by simply assuming that amount of energy is reflected diffusely however the rest is reflected specularly; where the sound particle is reflected with a Lambert's law in a specular or diffusive reflection [1]. Two reflection coefficients can be defined as: the specular "s" and the diffuse " $\mathrm{d}$ " where $\mathrm{s}+\mathrm{d}=1$ [2], diffusing is described by sound reflection in all directions from its original.

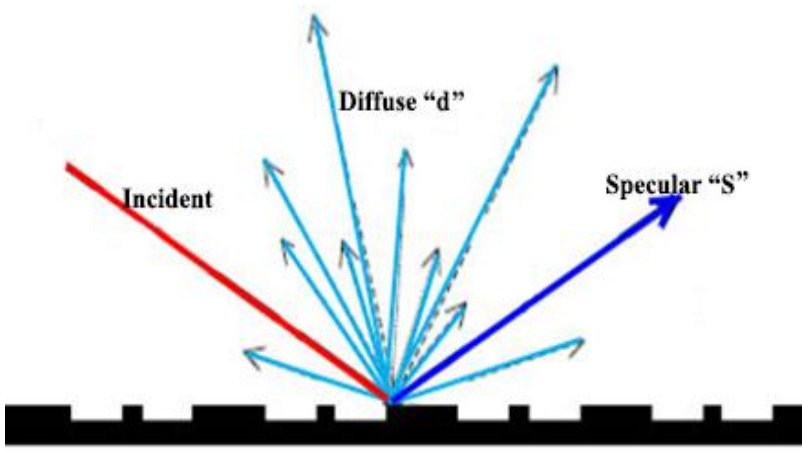

Figure 1 specular and diffuse reflection from façade surface [Source: M.R.Ismail, 2005, by researcher]

Diffusion behavior in urban streets caused by building facades plays a major role in street canyon noise propagation [3]. The impact of scattering caused by building facades on noise levels depends on the acoustic characteristics of urban streets, scattering causes an increase of noise levels at short distances, and a decrease at larger distances; the range of increase is higher in high-facade streets [4]. Noteworthy, several commercial sound prediction packages have limited calculations for urban sound propagation, because of taking into 
consideration the specular reflections and ignoring the scattering behavior on the façades, or things preventing ray paths.

Many parameters should be taken into consider when modeling sound propagation in a street; like street width, façade height, absorption coefficient of the ground, absorption coefficient of the facades, diffusion coefficient of facades, and absorption coefficient of the obstructions.

Previous works determined calculation methods for predicting the sound fields of urban areas according to the acoustical characteristics of the street boundaries. Image source and ray tracing method have been used for fundamental analysis of urban areas with perfectly smooth and geometrically reflective façades [5] [6], they offer a good compromise between accuracy and computation times [7].

Another previous work simplified the effect of changing in façade pattern on the acoustic protection process [8], in order to analyze the shadow zone resulted from varied configurations of façades buildings; as presented in Table 1.

Table 1 simple analysis of shadow zone depended on façade's pattern

[Source:L. Busa, S. Secchi, and S. Baldini,2010, by researcher]

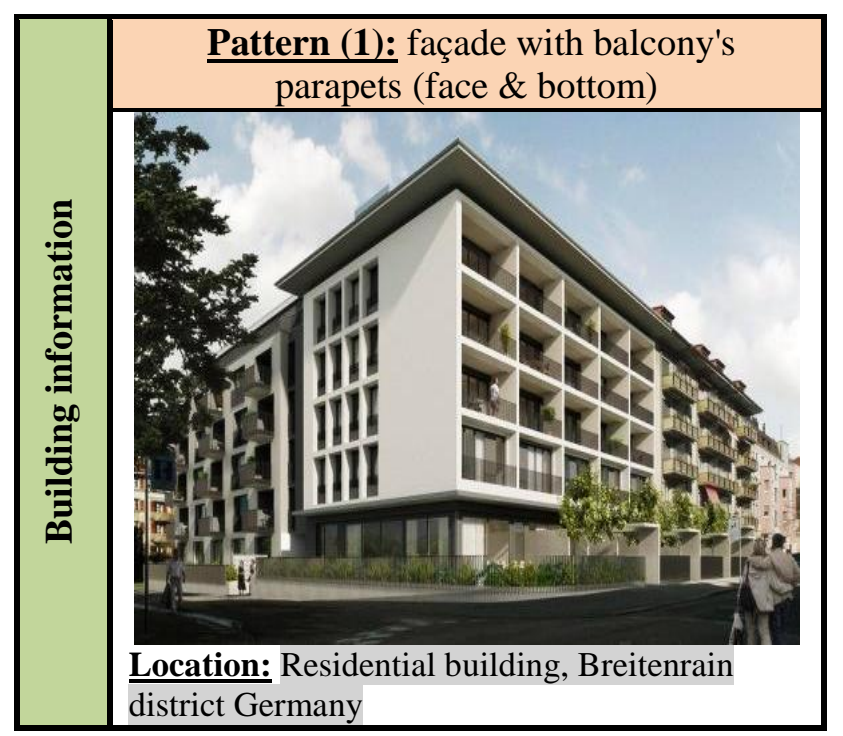

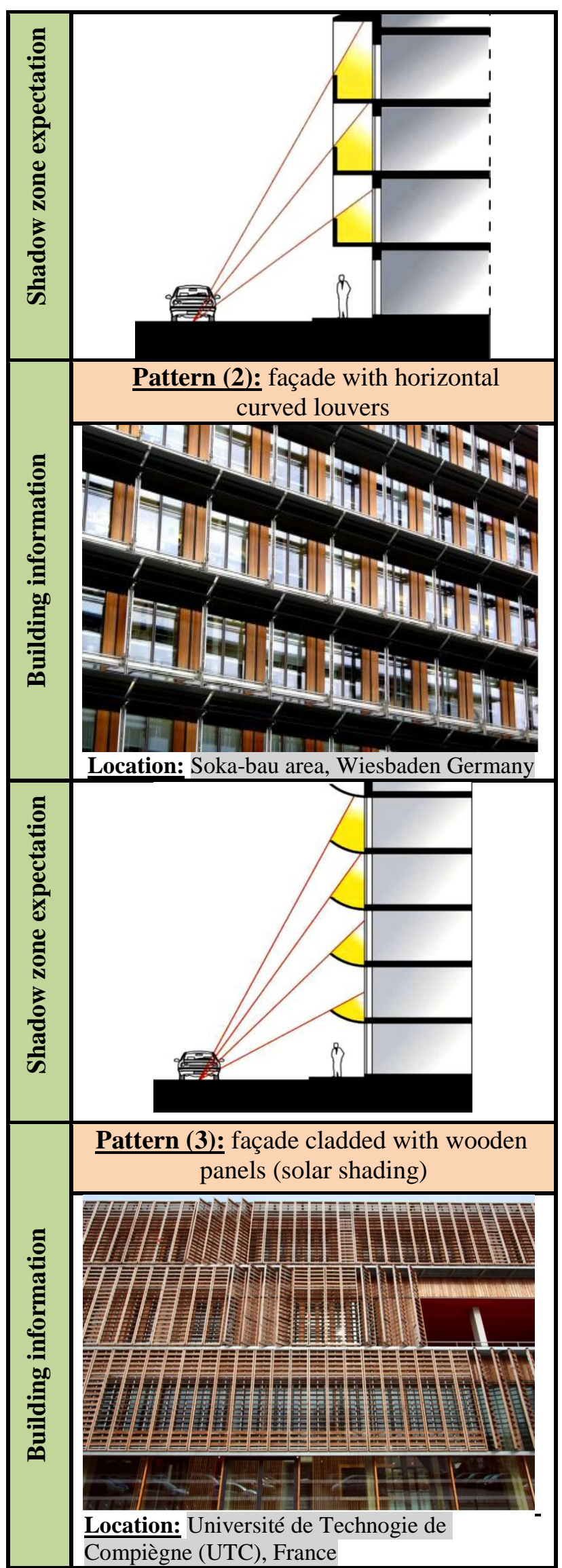




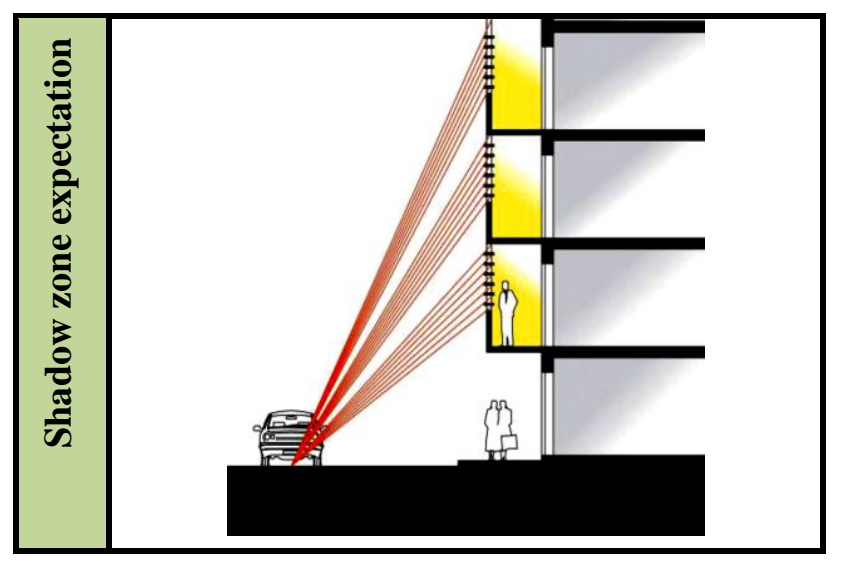

\section{ROLE OF FAÇADE GEOMETRIC CHARACTERISTICS IN NOISE CONTROL}

Residential façades can play a significant role in the sound fields in urban streets and the acoustical characteristics of street canyon would be different according to the relation between façade's height and street width (H/W ratio), also the analysis of residential façade geometric characteristics and features of architectural configuration especially in Egypt should be contributed in decisions of noise control due to its effect on sound reflections and noise levels.

Residential façade's elements of architectural configuration for example is suggested by researcher as showed in Figure 2 where the vertical and horizontal structure formation by columns or slabs or other devices, the recess like windows tiles arrangement, and the protrusions like balconies. All of these previous elements can be used to influence the behavior of sound and to treat sound aberrations as an approach to provide comfortable sound environment in urban areas.

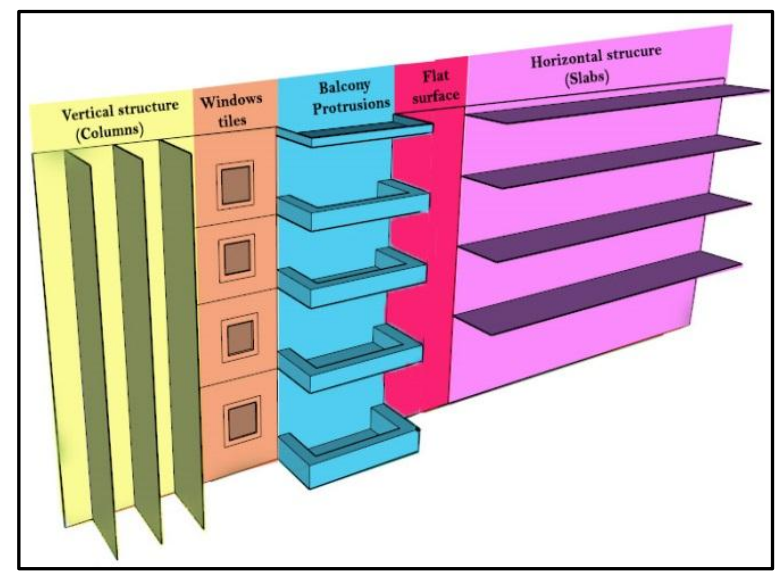

Figure 2 Residential façade's elements of architectural configuration

[Source: by researcher]

\subsection{Effect of façade's balcony parameters on noise levels}

When external facades are flat surfaces, it causes reflecting noise in specular manner. However the main type of reflections on exterior facade of urban buildings is scattering, because of its irregularities (decorative elements, windows, balconies, etc.) are comparable to the sound wavelengths [3]. Previous studies resulted that urban frontages can define the acoustical environment of urban spaces. This is due to the acoustical characterization of its elements form and materials.

Diffusers can be used on balcony fronts to reduce the noise reflected back down to the street [9], like vertical garden elements in balcony fronts, as an aesthetically appealing visual and pollutant filter between dwelling occupants and the street, see Figure 3. As well, absorbers can be located on balcony soffits lined with acoustic panels to absorb sound and reduce sound reflection back into the dwelling, see Figure 4.

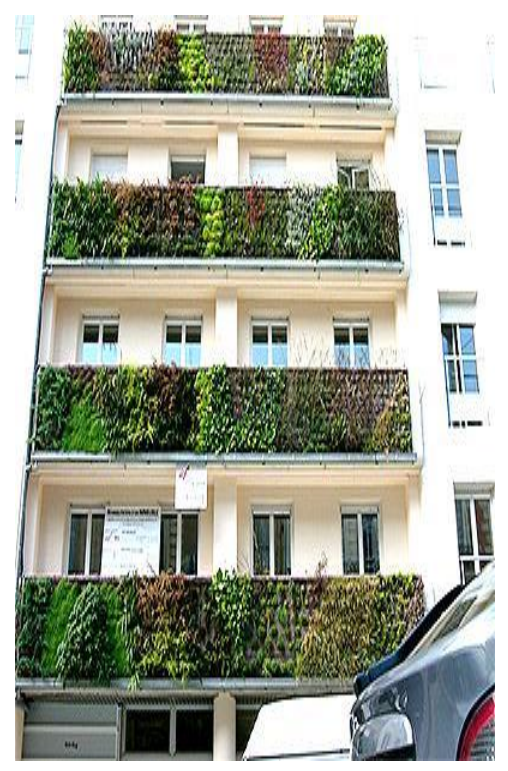

Figure 3 Immeuble ICF, Bordeaux., vertical elements in balcony front as diffusers

[Source: http://mindfuldesignconsulting.com/ vertical-gardens-as-design-element/] 


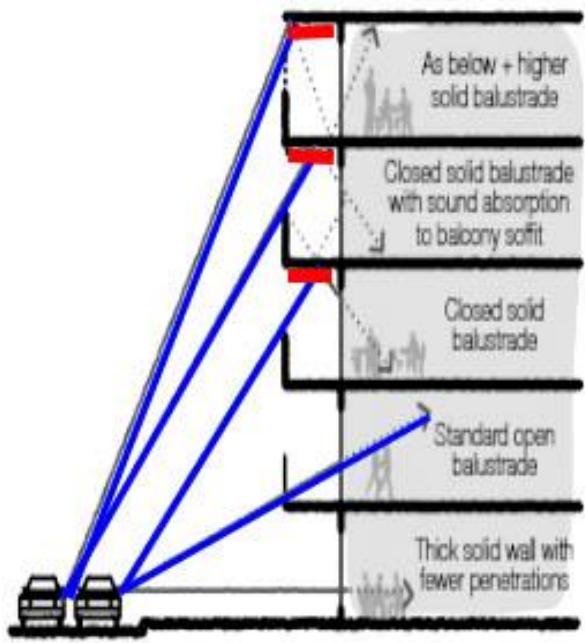

Figure 4 balcony soffits lined with acoustic panels as absorbers

[Source: Government of South Australia, Department of Planning, 2013, by researcher]

For medium to high rise mixed-use buildings, podiums can be used to shield residential levels above from noise. Non-residential uses at ground level, such as commercial at the front of the site, with residential floors set back, will increase the separation distance and shield the upper floors from the noise source, It can also help activate the streetscape if well designed as well as contributing shielding upper floors [10], see Figure 5.

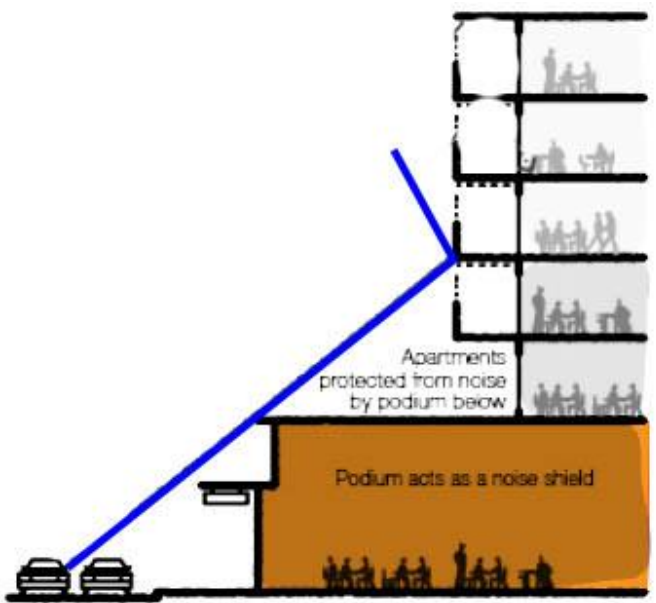

Figure 5 podiums act to shield upper residential floors [Source: Government of South Australia, Department of Planning, 2013, by researcher]

Balconies may act to reflect noise directly into the interior of the dwelling from the balcony above as shown in Figure 4. Some of design features to help control noise and air quality impacts are: the use of solid handrails incorporated into balconies as a shield to the noise source, as shown in Figure 6, and the use of 'winter garden' balconies with operable glass screens that can create a fully enclosed indoor-outdoor space, see Figure 7.

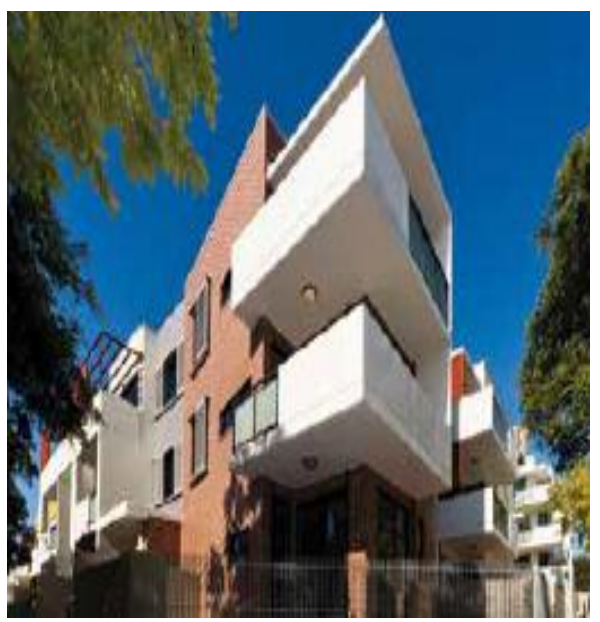

Figure 6 Deep balconies with solid handrails protect from outdoor noise

[Source: Government of South Australia, Department of

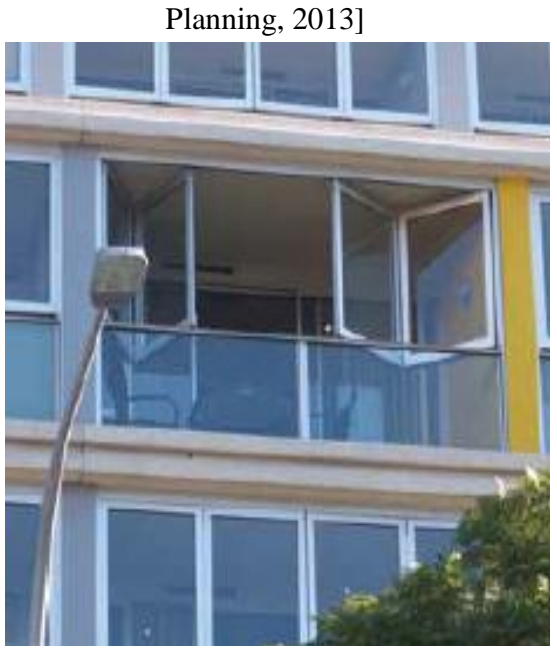

Figure 7 winter gardens balconies as a way of reducing noise entering dwelling

[Source: Government of South Australia, Department of Planning, 2013]

The screening effect of balconies has been investigated using either scale models or computer simulations. The efficiency of six different balcony forms for reducing exterior noise for an apartment complex was lastly investigated by scale models [11], and it was found that parapets design is effective in reducing noise based on varying in its characteristics. Parapet can be considered a sound barrier in the front of the balcony that gave more sound attenuation, and using of combination of absorbing surfaces on the ceiling and the parapet gave high noise reduction, which can be useful in high-rise building where tall barriers cannot be built, see Figure 8 . 

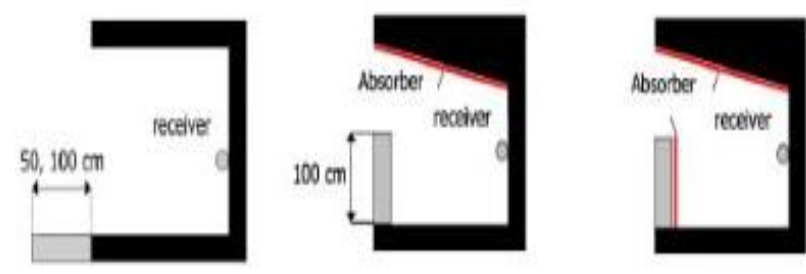

Figure 8 steps to effectiveness balcony form to reduce noise [Source: Lee, Kim, 2007, by researcher]

The potential efficiency of treating some of surfaces of the building balcony with absorbing materials as shown in Figure 9; as a method to reduce noise was investigated by numerical modeling [12] [13], and resulted that the choice of treating the ceiling or the rear wall of the balcony is the most effectiveness way to reduce noise; reduction range is about $10 \mathrm{~dB}(\mathrm{~A})$, and that the primary effect of an absorbent is to reduce the high frequency.

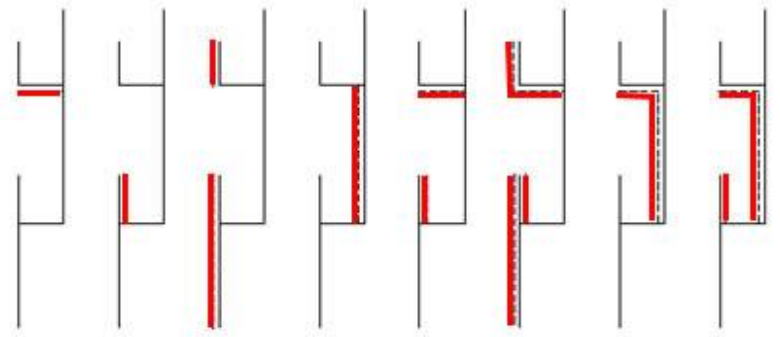

Figure 9 Treatment of balcony surfaces with absorbing material

[Source: Hothersal, 1996, by researcher]

One of most important configurations of balcony design which effect on noise reduction is inclined angle of balcony ceiling, see Figure 10. Three inclined angles of balcony ceiling were tested $(50,10 \mathrm{o}$, and $15 \mathrm{o})$ with different depths $(1,2$, and $3 \mathrm{~m})$ in previous study [14], and it showed that maximum reduction is obtained at higher floors with $2 \mathrm{~m}$ balcony depth and more. The useful of inclined balcony ceiling is to change the direction reflected sounds away from the balcony back wall.

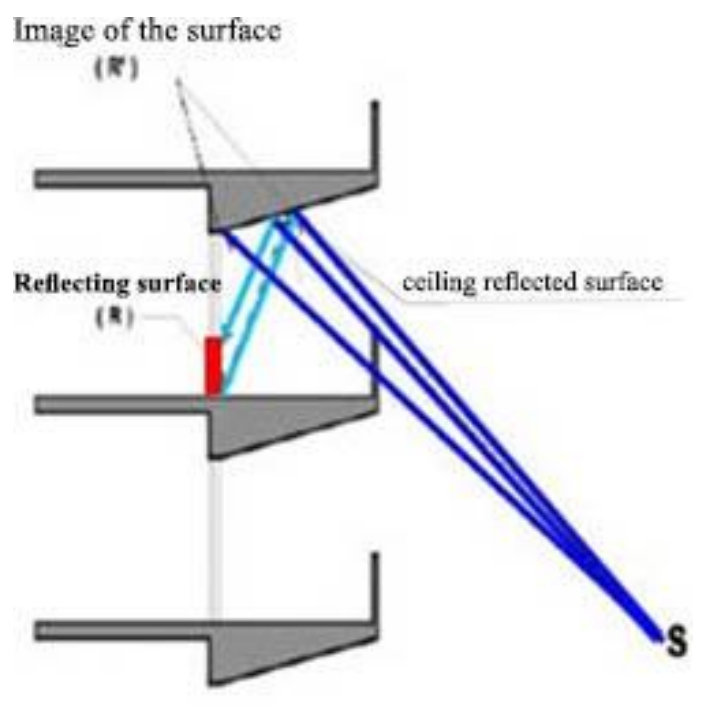

Figure 10 the effect of balcony ceiling form on reception surface of back wall

[Source: H.H.El Dien, 2004, by researcher]

Another concept by using various types of parapet forms to increase the shielding effect to protect the balcony back wall from the traffic noise was presented in previous study models [15]. when the effect of three balcony depths (with 1,2, and $3 \mathrm{~m}$ ) and two parapet (with $15 \mathrm{o}$, and 30o) inclinations was evaluated, the increasing of protection ranges from using various depths of parapet can be obtained, and the additional protection up to 8 $\mathrm{dB}(\mathrm{A})$ can be obtained by inclining parapet as a concept of increasing the shadow zones, see Figure 11.
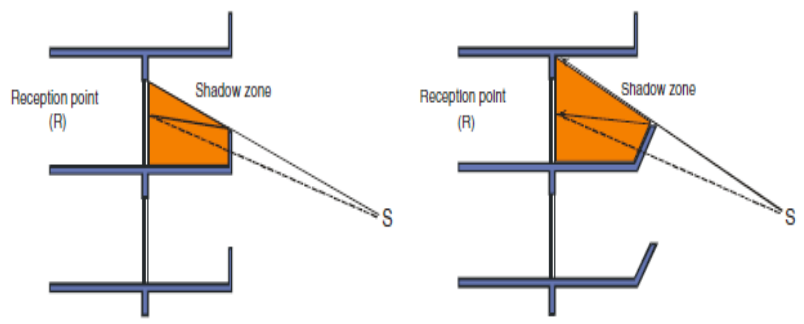

Figure 11 the increasing of shadow zone in balcony by inclining balcony parapet [Source: H.H.El Dien, 2005]

Effectiveness of balcony form as screening device for transportation noise was examined by using scale model for four different types of balcony forms as shown in Figure 12, which are commonly found in Hong Kong [16]. And it was found that the front panel of the balcony acts like screening device, while the effect of side walls of the balcony was insignificant. Due to upper balcony reflection, Balconies without a front panel do not offer any acoustic protection, especially for a distant noise source. 

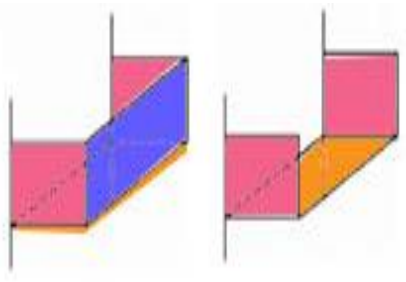

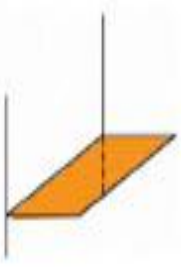

(a) Closed

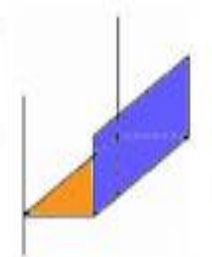

(b) Side-bottom

(c) Front-Bottom

(d) Botom
Figure 12 four types of balcony forms

[Source: S.Tang, 2005, by researcher]

\subsection{Forming façade's surface by acoustic diffuser}

Like in room acoustics, in the aim to reduce noise level within street, the effective strategy based on correcting the acoustic properties of urban spaces can be used. Few studies suggested using absorption and diffusion devices as a façade treatment to reduce noise propagation, like absorbent patches on the façades, and on the ground [17] [18] or oriented ones on the façades [19].

As a useful solution for urban noise problem, the use of acoustic diffusers based on quadratic-residue diffuser was proposed to produce optimum diffusion for the frequency of the road traffic spectrum [20] [21]. Recently, the (QRD) quadratic residue diffusers or Schroeder diffusers is commonly used.

It's a good mean to find a new surface geometry that could merge between the diffusion characteristics of MLS (Maximum length sequence diffusers) and wide range of frequencies.

Meaning of diffusers; in the aim to understand the use of façade diffusers, let's know the meaning of it; these are used to treat sound aberrations such as echoes. It's a good adjunct choice to sound absorption for the reason that it does not dismiss sound energy, but it reduces different of echoes and reflections while let space has a live sound.

\section{$\underline{\text { Schroeder diffusers' types are: }}$}

- 1D Schroeder diffusers (single plane diffusers) consists of a series of wells with same width and different depths determined by QRD sequence, and the wells separated by thin fins as shown in Figure 13. Sound wave propagates within the wells acting as a planar surface, then reflects from its bottom and reradiate into the lobe. The external sound pressure from diffusers depended on the interference between the radiating sound waves from each well with their different depths; all these waves have the same energy but a different phase [22].

- 2D Schroeder diffusers (multi plane diffusers) consists of two plane devices; one in the x-direction and one in z-direction where they gives scattering in multiple grating lobes on hemisphere, see Figure 14. The pattern of 2D diffusers by quadratic residue sequence can be produced using QRDude calculator - free software depending on " $\mathrm{N}$ " the number of wells, design frequency in "Hz", and well's width and depth. Compared to a reflective surface, that causes specular reflection through reflected angle of the energy equals to the incidence one, however a diffusor radiated the sound energy in all directions leading to a big diffusive environment.

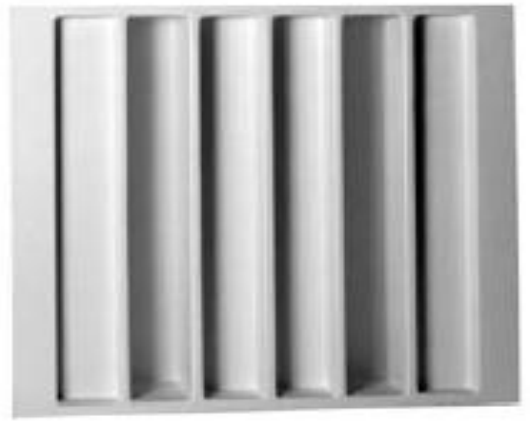

Figure 13 1D Diffusers; modulated diffusers [Source: acoustic absorbers and diffusers, T. J. Cox, and P. D'antonio, 2009]

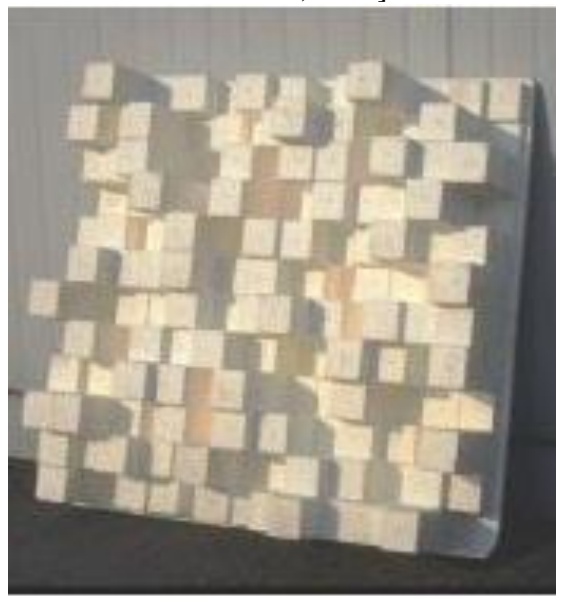

Figure 14 2D Diffusers; skyline diffusers

[Source: acoustic absorbers and diffusers, T. J. Cox, and P. D'antonio, 2009]

The use of acoustic diffusers based on quadraticresidue sequence of 2D Schroeder diffusers (skyline diffusers) were proposed in a previous experimental study [23] as shown in Figure 15 with a relative surface larger than $20 \%$. A positive effect can be observed, and resulted that diffusers are well design aid for the reduction of road traffic noise. And if possible they are located on the lower part of the façades, a significant noise reduction can be observed on the sound attenuation 
in a street, and by adding sound absorption on diffusers, it increases the noise reduction [24].

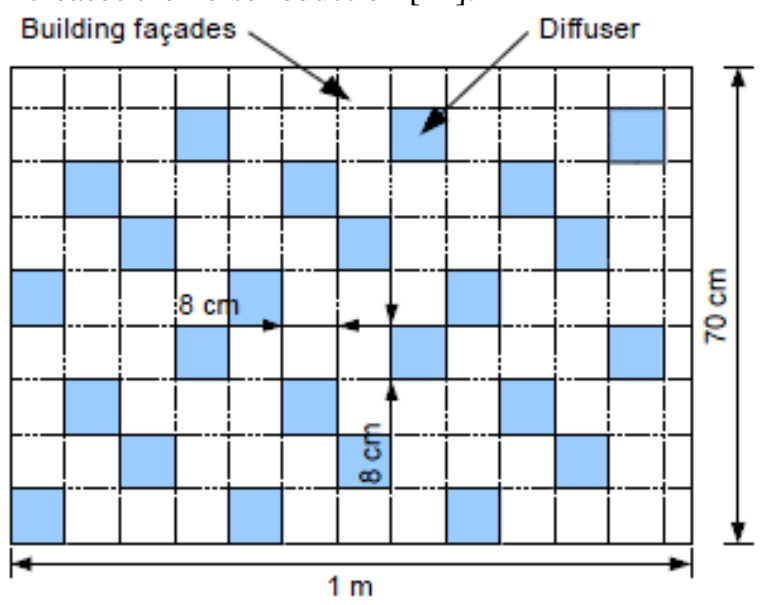

\section{Figure 15 An arrangement of diffusers repeated along façade surface \\ [Source: Picaut, 2010]}

The experimental investigation is suggested to check the effect of acoustic diffusers in streets, using scale models with and without diffusers comparing to in situ measurements [23], the results show a positive effect on sound attenuation in street with diffusers, for the frequency ranges for which the diffusion coefficient of the diffuser is the largest. And the effect is stronger on the reverberation time because the diffusers reduce the occurrence of flutter echoes.

A statistic distribution was proposed to simulate a kind of French architectural façade in a previous work [25] which was simply modeled by an arrangement of wooden cubes distributed side by side in a 1:50 scale model of a street as shown in Figure 16 that was easily split into façade's elements like (windows, balconies, frontage ... ) in order to compare with real measurements in full scale, and to reproduce acoustic fundamentals in streets such as multiple reflections, and diffuse-scattering by façade irregularities.

The statistical disposition of the wooden cubes in the scale model and the façade irregularities in the real environment produce diffusion sound field that cause few differences in sound attenuation between the two measurements on the traffic noise frequency range [250:5000 Hz] especially for the receivers close to the source, because of the first reflections becomes greater than the sound energy of the diffusion field. This work finally recommended taking a larger scale factor (e.g. 25-40) or a higher energy sound source because of appearing the problem of atmospheric attenuation.

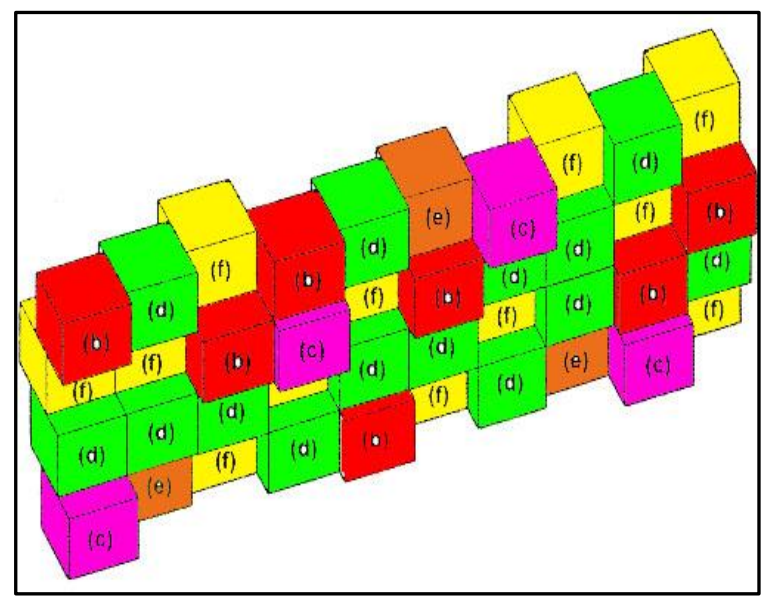

Figure 16 simplify the façades architectural complexity with statistic distribution of wooden cubes [Source: Picaut, 2001, by researcher]

\subsection{The effect of windows arrangement on noise levels}

One of main elements of façade's architectural details is windows tiles arrangement. The most common pattern of the placement of them is nearly periodic structure; in the vertical direction it has the same arrangement because of typical vertical floor heights, but in the horizontal direction it has different order vary from building to building. Finally, the arrangement of windows on façade's surface compared to the materials' characteristics of windows can be considered a neglected issue that effect on indoor noise levels and sound transmission loss.

In order to demonstrate the effect of windows arrangement of building's façade on the scattering properties of façade, one previous study [26] simulated the prediction of building façade with three consecutive glass windows with metallic frames separated by vertical masonry strips and compared with the main case of flat façade. The results showed that façade's windows array make diffraction orders instead of diffuse scattering, and the study presented a single smoothed scattering coefficient depending on the angle of incidence in order to be included into a ray tracing code.

\section{ANALYSIS OF EGYPTIAN RESIDENTIAL FACADES' PATTERNS DEPENDING ON THE LIMITS OF CONSTRUCTION CODE}

Egyptian façade's patterns seem to be typically designs and rhythmic formation with their typical floors, balconies, and windows. The Egyptian code for construction determined some geometric parameters that organize the design process. Before analyzing the 
patterns of façades, we should understand the limits of geometric aspect that were determined by Code.

By analyzing the façade's patterns at Egypt which its formation recently is depending on structural concept, it will finally derive the geometric parameters of façade shape that will be the geometric inputs of computer simulation.

\subsection{Limits of façade's height}

The minimum net internal height per floor measured from the level of the finishing surface of the ground until the inner apparent roof equals $(2.7 \mathrm{~m})$ in all floors as determine in (rule 93). It may be less the height to (2.3 m) for the entrances, internal corridors, bathrooms, and others.

And thus to simplify calculations, the height of floor in residential façades can be considered $(3 \mathrm{~m})$. For calculating the residential façade's total height, Code determined that the total height equals one and half times of street's width [Façade height $(\mathrm{H})=1.5^{*}$ street width $(\mathrm{W})]$ that must not be exceed $(36 \mathrm{~m})$ as maximum limit.

The previous limits of heights can be the base of design parameters in the vertical direction when taking a decision to form façades with horizontal elements that fit with the dividing of typical floors along façade's height, see Figure 17.

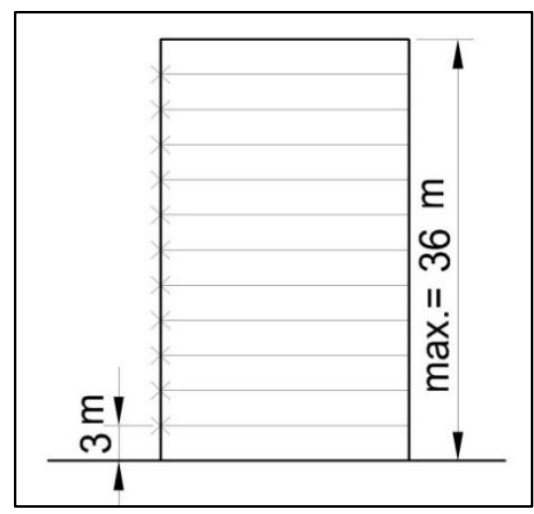

Figure 17 - limits of one floor height and total façade height

[Source: by researcher, Egyptian construction code, 2009]

\subsection{Limits of façade's width}

Residential façade's width has different dimension vary from block to block where its average range is between $(10 \mathrm{~m})$ to $(20 \mathrm{~m})$ relating to the rules of dividing and planning residential blocks. Where the rule 26 in the fourth chapter about detailed planning determined the area of a piece of land in a city is at least $(120 \mathrm{~m} 2)$, and determined the residential façade width on a street city is (10m) as a minimum limit with a length of residential block is no more than $(250 \mathrm{~m})$ in the city.

But in order to determine total façade's width, we can explain the limits of internal space's width that found in the code and by the repeat of the width module depending on the design components; the total width of residential façade will be calculated.

Rule 94 determined the widths of inner spaces; minimum distance of the bedrooms and livings is $(2.5 \mathrm{~m})$ with $(7.5 \mathrm{~m} 2$ area), minimum distance of bathrooms is $(1.2 \mathrm{~m})$ with $(1.5 \mathrm{~m} 2)$ area, and minimum distance of kitchens is $(1.5 \mathrm{~m})$ with area is $(3 \mathrm{~m} 2)$, which make the façade that includes residential rooms view on a street are divided into module $(2.5 \mathrm{~m})$ and multiples or divisible by this number, see Figure 18.

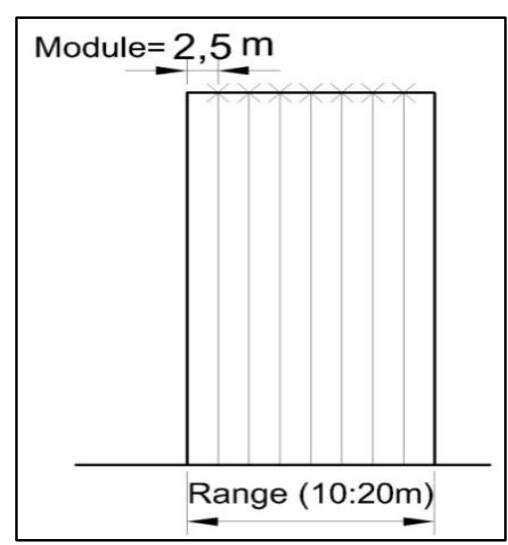

Figure 18 - limits of façade width and dividing module [Source: by researcher, Egyptian construction code, 2009]

\subsection{Limits of façade's protrusions and recesses}

To find out the requirements of designing windows and balcony's handrail, rule 96 determined the area of room's window is $(8 \%)$ of total room area, and the distance height under the windows must be at least $(0.9 \mathrm{~m})$. And in case of the presence of balconies and terraces in front of the windows from the outside, the height of handrails (inhibitors of falling) is at least $(0.9 \mathrm{~m})$ for the first five floors, see Figure 19.

The height of handrails is increasingly by $(5 \mathrm{~cm})$ for each floor from the following floors with $(1.2 \mathrm{~m})$ as maximum, and thus to simplify calculations, the height of Handrails in balconies can be considered (1m).

To find out the requirements of designing protrusions by balconies and cornices, rule 103 determined the forming of protrusions on the buildings façades according to the following conditions: 


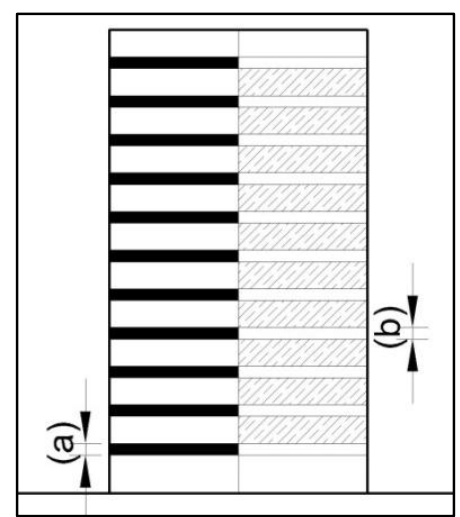

Figure 19 - (a) height of handrails - (b) height under the windows

[Source: by researcher, Egyptian construction code, 2009]

- Forming balconies on the façade surface with depth $(10 \%)$ of street width; protrusions by balcony depth are not to exceed $(1.25 \mathrm{~m})$ on facade surface. It is not allowed to make protrusions by balconies or verandas on a street whose width is less than $(6 \mathrm{~m})$. See Figure 20.

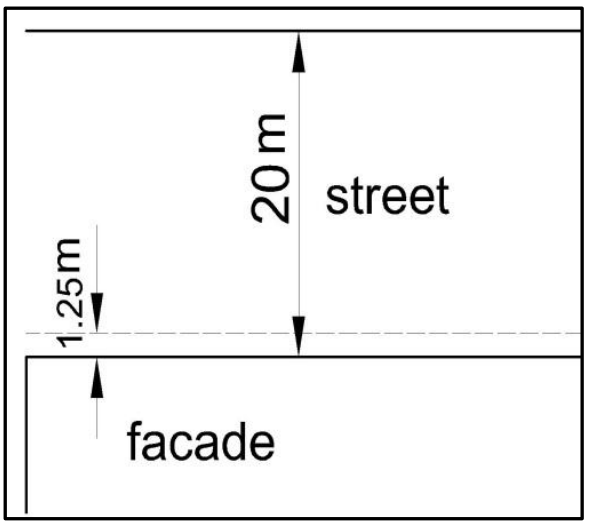

Figure 20 - limits of a balcony depth on façade surface [Source: by researcher, Egyptian construction code, 2009]

\subsection{Analyzing Egyptian residential façades patterns}

To analyze common patterns of residential facades in Egypt; especially in Port Said city, we should explore the housing distribution map and detect the main types of housing buildings. Port Said city is divided into seven districts (Sharq- Arab- Manakh- Zuhur- Dawahy- JanubGharb) by reference to GIS maps in Port Said governorate. Through a personal observation in the field visit and with reference to a previous search [27], researcher could divide the housing building into three types (Governmental- Cooperative- Private).

- The Governmental housing; Government and Urban Communities Authority take the responsibility of implementation often through uniform residential models serving low-incomes.
- The Cooperative housing; some of the cooperative association and Housing \& Development Bank take the responsibility of implementation through an economic view point.

- The Private housing; some of owners association make an individual design attempts in new towers.

The majority of housing buildings is the governmental housing models for low-incomes; most of them are located in Zuhur, Manakh, and Dawahy district as shown in Figure 21. Therefore the analysis focuses on this type of housing buildings and its façade's pattern.

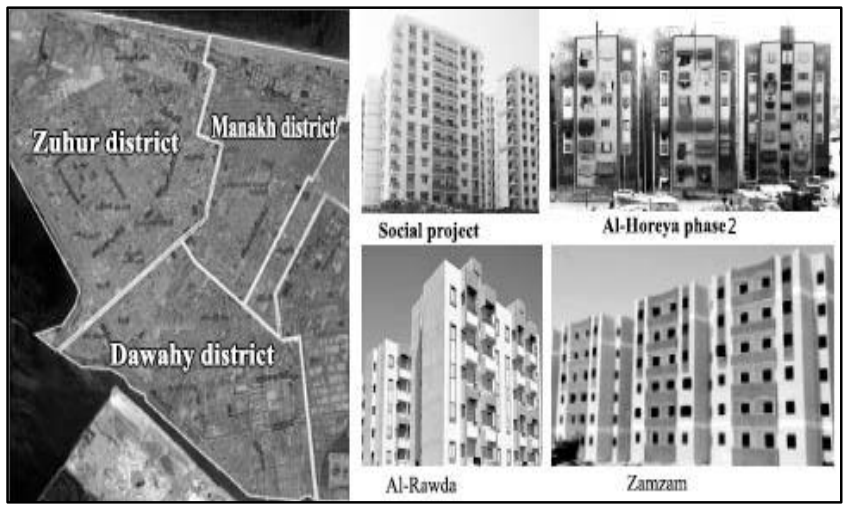

Figure 21 - the governmental housing models for lowincomes

[Source: By researcher]

The general character of the governmental housing buildings is low-cost; in terms of the design in minimum areas of spaces, simple protrusions on façade surface by using balconies, and the aggregation of the units to achieve the most possible use of the land. The analysis of façade patterns of governmental housing is based on five points as follow: 


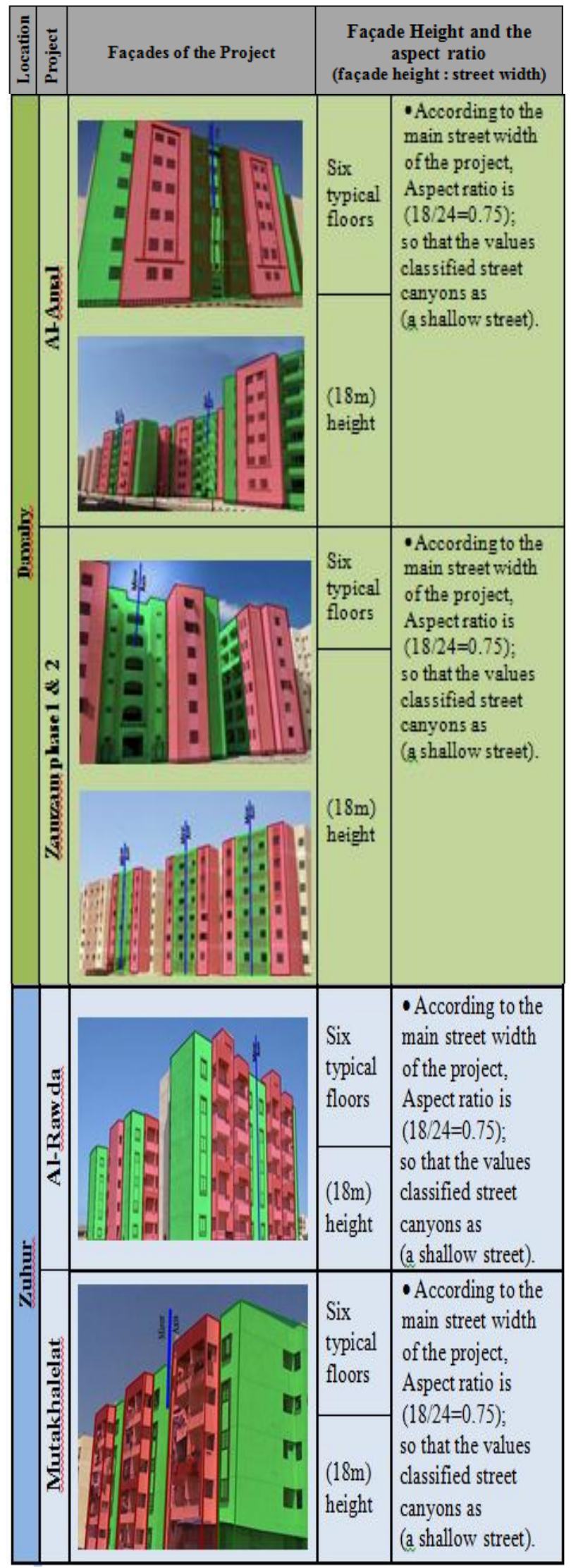

- Table 2 .

- Façade boundary and the sky line shape, Table 3.

- Façade segments splitting into sub-surfaces

- Repetitive protrusions and structure elements

- Pattern of the windows arrangement

Table 2- Analysis of façade height of governmental housing buildings

[Source: Researcher]

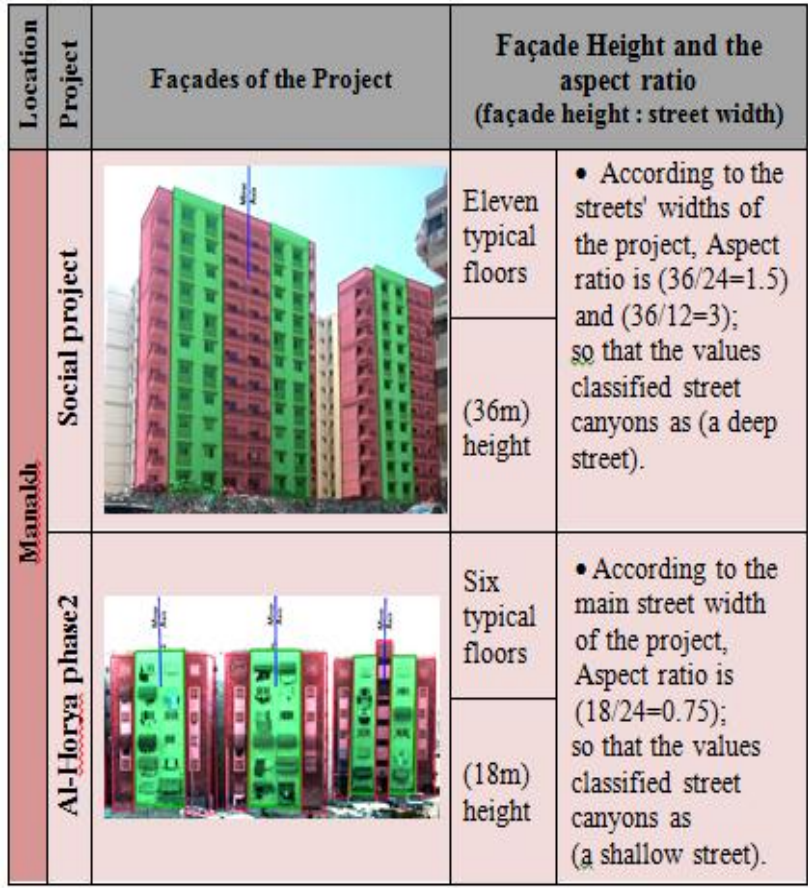


Table 3- Analysis of façade boundary and the sky line shape

[Source: Researcher]

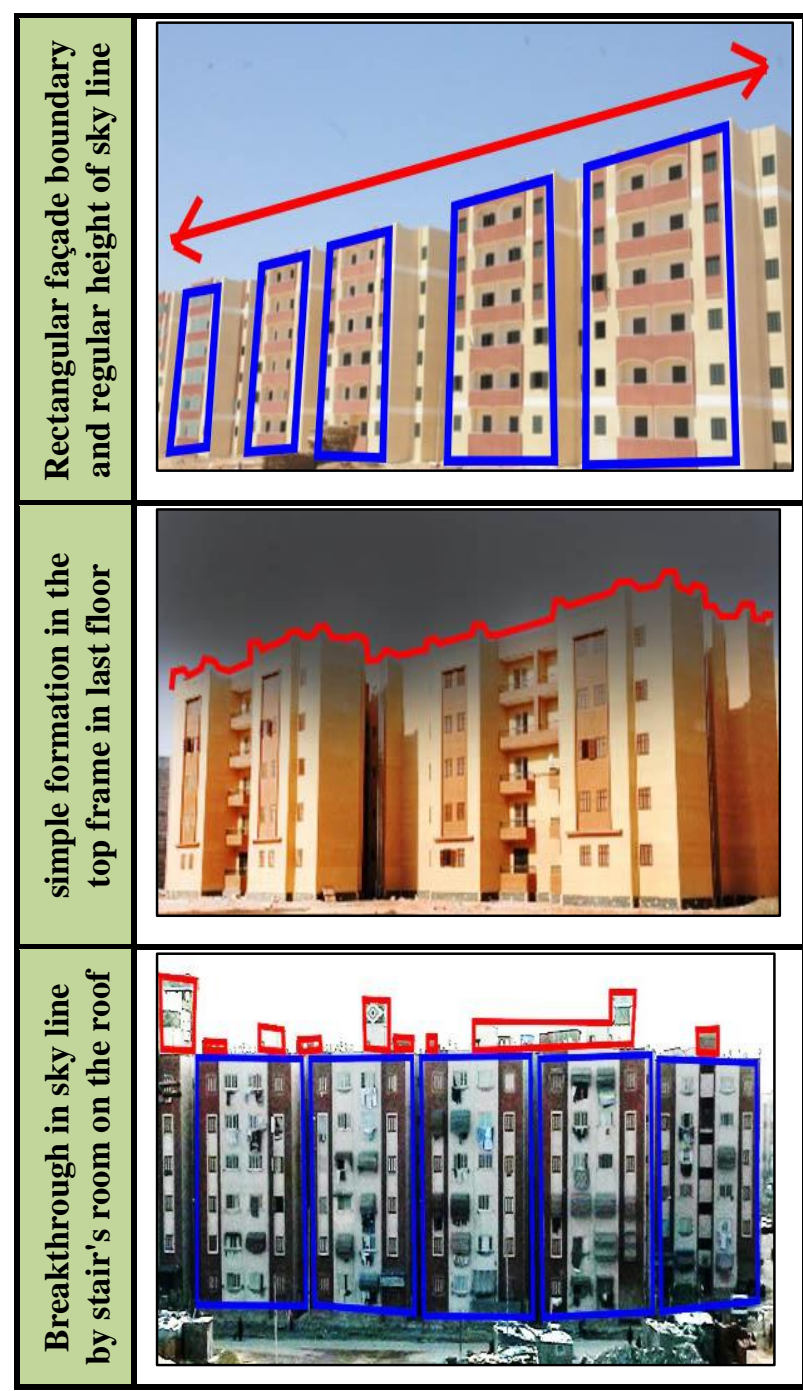

The pattern of splitting façade's surface into segments (sub-surfaces) whether it was vertical or horizontal is depended on the limits of widths and heights that were determined in the code. The horizontal direction is dominated by the symmetrical division. Façade's surface was divided according to the module of interior spaces' width either by showing only a single segment of interior space or combining two interior spaces to widen the segment's width, as shown in Figure 22, the red segment is break-out and the green segment is set-off.

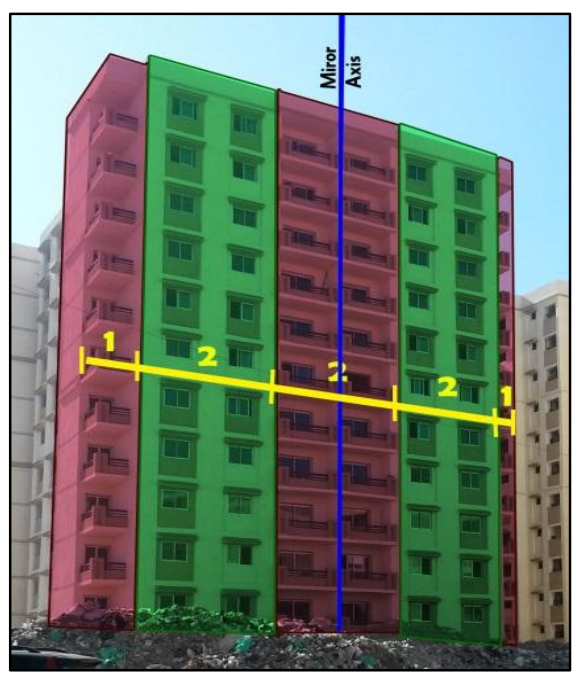

Figure 22 - The symmetrical division with single and double segments

[Source: Researcher]

The main feature of the detailed formation on the residential façade's surface is controlled by the structure system elements. The structure system elements along façade's height consist of repeated slabs of the typical floors by using the module of floor height $(3 \mathrm{~m})$ which effect on the formation by using repetitive balconies' parapets and the formation by using the typically slabs break-out on façade's surface, see Figure 23.

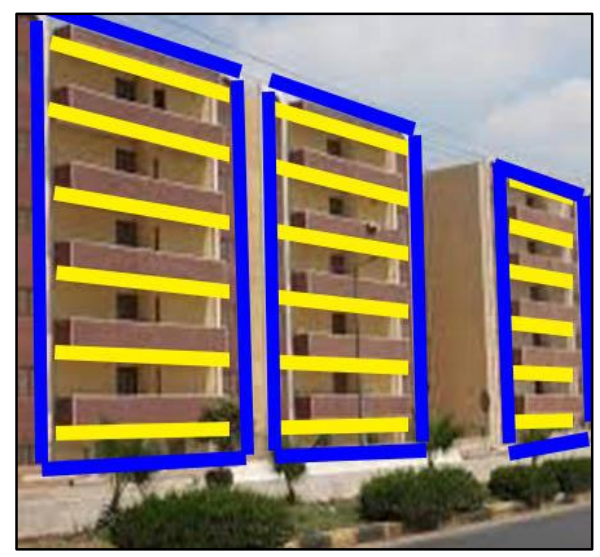

Figure 23 - formation by using repetitive balconies' parapets

[Source: Researcher]

Also the structure system elements along façade's width consist of repeated columns by using the limits of span's width which effect on the formation by using repetitive vertical modular units and the formation by using the columns break-out on façade's surface. And the mixture of using horizontal and vertical elements of the structure system can be used in the residential façades as shown in Figure 24. 


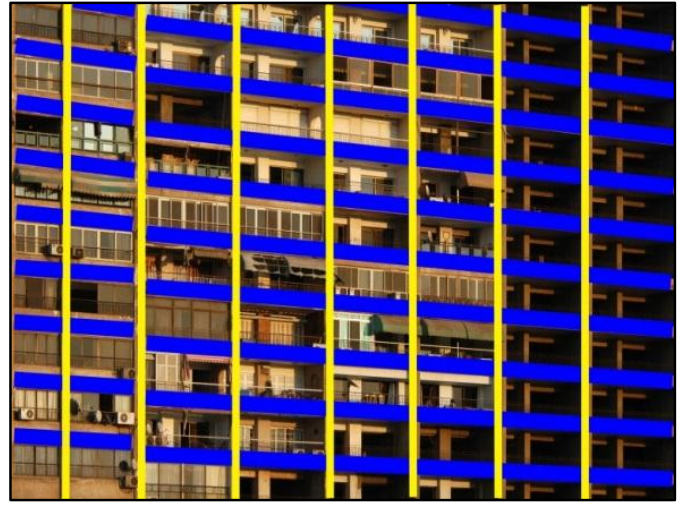

Figure 24 - mixture of horizontal and vertical elements of the structure system

[Source: Researcher]

Façade's Configuration provides a regular pattern of windows distribution which repeats vertically on each floor along façade's height $(3 \mathrm{~m})$ with the small windows area according to minimum limits from the code (10\% of room area), and which repeats horizontally on each space has a street-view along façade's width, see Figure 25.

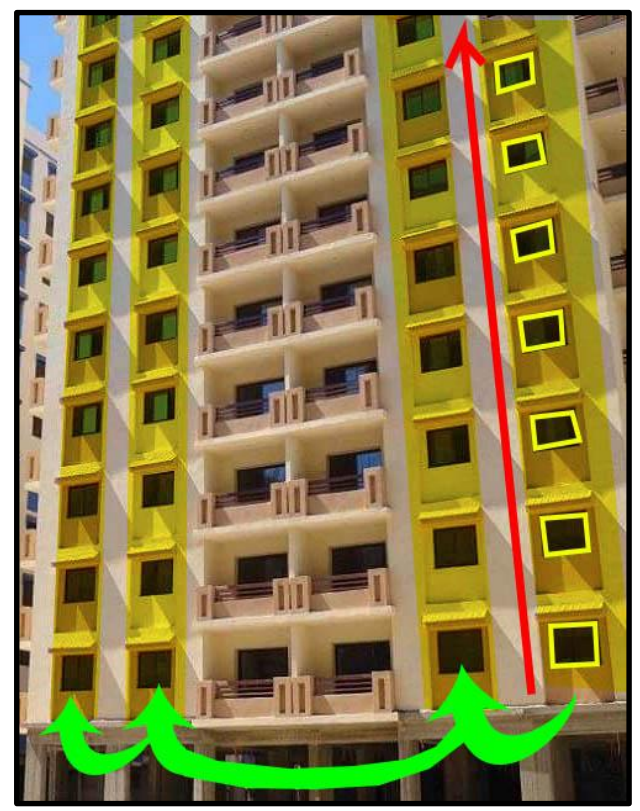

Figure 25 - a regular pattern of windows distribution [Source: Researcher]

\section{RESULTS}

1. Residential façade's elements of architectural configuration like vertical structure (columns), horizontal structure (slabs), and balcony protrusions play a significant role in the sound fields in urban streets as an approach to provide comfortable sound environment.

2. Summary of balcony's characteristics from geometric and acoustic aspects as shown in Table 4; illustrated the components of balcony and its effect on noise reduction that was determined by its shape dimensions and its acoustic properties.
Table 4 - balcony characteristics

[Source: by researcher]

\begin{tabular}{|c|c|c|c|c|}
\hline \multicolumn{5}{|c|}{ Balcony characteristics } \\
\hline \multirow{2}{*}{ parameters } & \multicolumn{2}{|c|}{ Parapet } & \multirow{2}{*}{ Ceiling (soffits) } & \multirow{2}{*}{ Rear wall } \\
\hline & Front & Side & & \\
\hline geometric & \multicolumn{2}{|c|}{$\begin{array}{l}\text { Solid or formed with }(0.5 \mathrm{~m}, 1 \mathrm{~m}) \\
\text { height but when inclined }\left(15^{\circ}, 30^{\circ}\right) \text { is } \\
\text { effective in increasing shadow zones } \\
\text { inside balcony }\end{array}$} & $\begin{array}{l}\text { Straight line with }(1,2,3 \mathrm{~m}) \\
\text { depth but when inclined } \\
\left(5^{\circ}, 10^{\circ}, 15^{\circ}\right) \text { is effective in } \\
\text { changing reflections away } \\
\text { from rear wall }\end{array}$ & $\begin{array}{l}\text { The height of } \\
\text { residential floor } \\
\text { (3m) }\end{array}$ \\
\hline & \multicolumn{2}{|c|}{$\begin{array}{l}\text { Parapet as a sound barrier gave high } \\
\text { noise reduction in high-rise building }\end{array}$} & \multicolumn{2}{|c|}{$\begin{array}{l}\text { Ceiling and rear wall is the most efficient in } \\
\text { terms of noise reduction }\end{array}$} \\
\hline acoustic & $\begin{array}{l}\text { - It acts like } \\
\text { screening } \\
\text { devices } \\
\text { - Using diffusers } \\
\text { from outside } \\
\text { and absorbers } \\
\text { from inside }\end{array}$ & $\begin{array}{l}\text { - Non-effective } \\
\text { in acoustic } \\
\text { protection }\end{array}$ & - Using absorbers & $\begin{array}{l}\text { - Using } \\
\text { absorbers }\end{array}$ \\
\hline
\end{tabular}

3. The use of acoustic diffusers based on quadraticresidue sequence on façade surface with a relative surface larger than 20\%; is well designed that presents a positive effect on sound attenuation in street. By adding sound absorption on façade surface diffusers increases the noise reduction.

4. Simplify the façades geometrical complexity as an arrangement of blocks is the simple way to simulate the architectural complexity of building facades, which is the fundamental cause of the sound diffusion in streets.

5. The general character of the governmental housing buildings is low-cost; in terms of the design in minimum areas of spaces, simple protrusions on façade surface by using balconies, and the aggregation of the units to achieve the most possible use of the land. The analysis of façade patterns of governmental housing is based on following five suggested points; concluded as shown in Table 5.

- Façade height and the aspect ratio.

- Façade boundary and the sky line shape.

- Façade segments splitting into sub-surfaces.

- Repetitive protrusions and structure elements.

- Pattern of the windows arrangement.

6. The importance of assessing façade formation influence on sound pressure levels in Egyptian urban streets that presented new tested configurations related to geometric aspects from Egyptian construction code and don't previously evaluated, the evaluation will presented in terms of:

- Formation with vertical and horizontal segments.

- Relative surface of the protrusions to total façade surface area. 
- Width to depth ratio of the protrusions.

- Absorption coefficient of façade's protrusions.

Table 5 - conclusion of the analysis of residential façade patterns

[Source: Researcher]

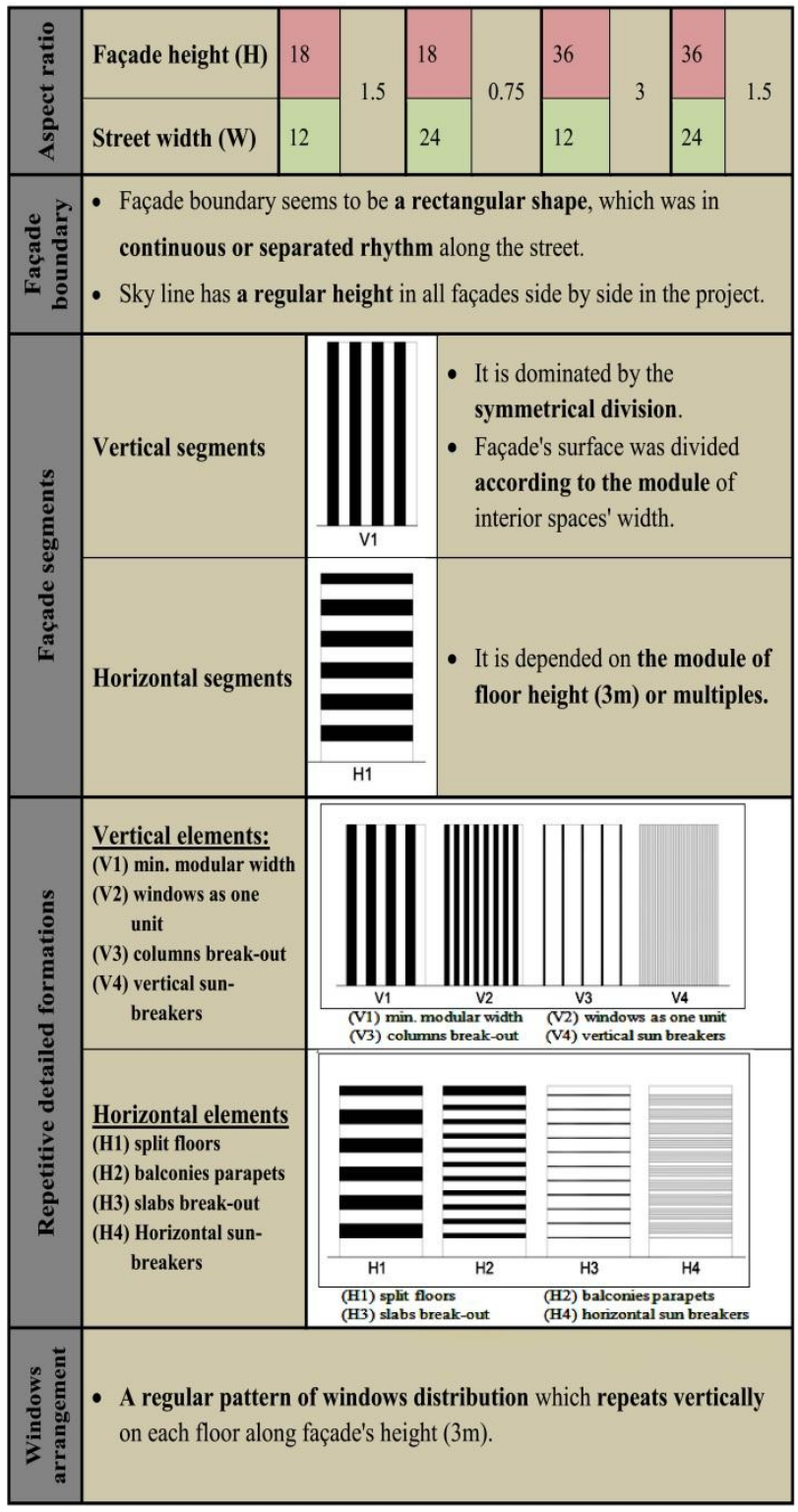

\section{CONCLUSIONS}

Façade's formations play an effective role for noise reduction when effect on noise reflections and noise levels in urban streets, its elements as balcony shape, limited dimensions, and specific materials can be well designed for this purpose. Egyptian façade's patterns with typically designs and rhythmic formation of floors, balconies, and windows determined the geometric parameters which organize the design process and should be evaluated in future studies concerning in assessing noise propagation through urban streets.

\section{REFERENCES}

[1] J. Picaut, and N. Fortin, "Manuel de référence du code SPPS," Ifsttar, 2011.

[2] M. Ismail, and D. Oldham, "A scale model investigation of sound reflection from building façades," Applied Acoustics, vol. 66, no. 2, pp. 123147, 2005.

[3] J. Kang, "Sound propagation in street canyons: Comparison between diffusely and geometrically reflecting boundaries," The Journal of the Acoustical Society of America, vol. 107, no. 3, pp. 1394-1404, 2000.

[4] H. Onaga, and J. H. Rindel, "Acoustic characteristics of urban streets in relation to scattering caused by building facades," Applied Acoustics, vol. 68, no. 3, pp. 310-325, 2007.

[5] D. Oldham, and M. Radwan, "Sound propagation in city streets," Building Acoustics, vol. 1, no. 1, pp. 65-88, 1994.

[6] K. Heutschi, "A simple method to evaluate the increase of traffic noise emission level due to buildings, for a long straight street," Applied Acoustics, vol. 44, no. 3, pp. 259-274, 1995.

[7] S. Kephalopoulos, M. Paviotti, and F. A. Ledee, "Common noise assessment methods in Europe (CNOSSOS-EU)," Common noise assessment methods in Europe (CNOSSOS-EU), pp. 180 p, 2012.

[8] L. Busa, S. Secchi, and S. Baldini, "Effect of façade shape for the acoustic protection of buildings," Building Acoustics, vol. 17, no. 4, pp. 317-338, 2010.

[9] J. Rathsam, and L. M. Wang, "A Review of Diffuse Reflections in Architectural Acoustics," Architectural Engineering -- Faculty Publications, vol. paper 14, 2006.

[10] G. o. S. Australia, "Reducing noise and air impacts from road, rail and mixed land use - A guide for builders, designers and the community," D. o. P. T. a. Infrastructure, ed., 2013.

[11] P. J. Lee, Y. H. Kim, J. Y. Jeon et al., "Effects of apartment building facade and balcony design on the reduction of exterior noise," Building and Environment, vol. 42, no. 10, pp. 3517-3528, 2007.

[12] D. Hothersall, K. Horoshenkov, and S. Mercy, "Numerical modelling of the sound field near a tall building with balconies near a road," Journal of Sound and Vibration, vol. 198, no. 4, pp. 507-515, 1996.

[13] J. Kang, Acoustics of Long Spaces: theory and design guidance: Thomas Telford, 2002.

[14] H. H. El Dien, and P. Woloszyn, "Prediction of the sound field into high-rise building facades due to its balcony ceiling form," Applied Acoustics, vol. 65, no. 4, pp. 431-440, 2004.

[15] H. H. El Dien, and P. Woloszyn, "The acoustical influence of balcony depth and parapet form: experiments and simulations," Applied Acoustics, vol. 66, no. 5, pp. 533-551, 2005.

[16] S. Tang, "Noise screening effects of balconies on a building facade," The Journal of the Acoustical 
Society of America, vol. 118, no. 1, pp. 213-221, 2005.

[17] J. Kang, Urban sound environment: CRC Press, 2006.

[18] V. Horoshenkov, C. Hothersall, and E. Mercy, "Scale modelling of sound propagation in a city street canyon," Journal of Sound and Vibration, vol. 223, no. 5, pp. 795-819, 1999.

[19] M. Hornikx, and J. Forssén, "A scale model study of parallel urban canyons," Acta Acustica united with Acustica, vol. 94, no. 2, pp. 265-281, 2008.

[20] T. J. Cox, and P. D'Antonio, "Acoustic Absorbers and Diffusers: Theory, Design and Application," Building Acoustics, vol. 12, no. 4, pp. 293-294, 2005.

[21] J. Picaut, and D. Scouarnec, "A numerical study of the use of acoustic diffusers to reduce noise in urban areas," Noise in the Built Environment, 2010.

[22] T. J. Cox, and P. D'antonio, Acoustic absorbers and diffusers: theory, design and application: CRC Press, 2009.

[23] J. Picaut, H. Hossam Eldien, and A. Billon, "An experimental study of the use of acoustic diffusers to reduce noise in urban areas."

[24] J. Picaut, and D. Scouarnec, "Using acoustic diffusors to reduce noise in urban areas," Acta Acustica united with Acustica, vol. 95, no. 4, pp. 653-668, 2009.

[25] J. Picaut, and L. Simon, "A scale model experiment for the study of sound propagation in urban areas," Applied Acoustics, vol. 62, no. 3, pp. 327-340, 2001.

[26] P. Pongsilamanee, and H. L. Bertoni, "Specular and nonspecular scattering from building facades," Antennas and Propagation, IEEE Transactions on, vol. 52, no. 7, pp. 1879-1889, 2004.

ح. م. ص. الصمتي، “تأثثير السياسات و التوجهات الإقتصادية على [27]

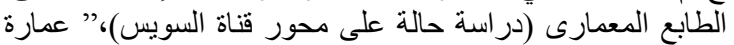

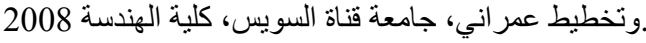

